Received February 8, 2019

Revised April 13, 2019

Accepted May 1, 2019

\section{Corresponding author}

Gyu-Sam Hwang, M.D., Ph.D.

Department of Anesthesiology and Pain Medicine, Laboratory for Cardiovascular Dynamics, Asan Medical Center, University of Ulsan College of Medicine, 88 Olympicro 43-gil, Songpa-gu, Seoul 05505, Korea

Tel: 82-2-3010-3868

Fax: 82-2-470-1363

E-mail: kshwang@amc.seoul.kr ORCID

https://orcid.org/0000-0002-3627-1107

\title{
Preoperative echocardiographic evaluation of cardiac systolic and diastolic function in liver transplant recipients with diabetes mellitus: a propensity-score matched analysis
}

\section{Hye-Mee Kwon, Youngil Jeong, Kyoung-Sun Kim, Kyeo-Woon Jung, Young-Jin Moon, and Gyu-Sam Hwang}

Department of Anesthesiology and Pain Medicine, Laboratory for Cardiovascular Dynamics, Asan Medical Center, University of Ulsan College of Medicine, Seoul, Korea
Background: Diabetes mellitus (DM) increases risk of heart failure. It has been shown that diabetes leads to DM-cardiomyopathy, characterized by systolic and diastolic dysfunction. Pre-transplant diastolic dysfunction, has been associated with poor graft outcome and mortality. We assessed the hypothesis that end-stage liver disease (ESLD) patients with diabetes (DM-ESLD), have more advanced cardiac systolic and diastolic dysfunction, compared to ESLD patients without diabetes (Non DM-ESLD).

Methods: We retrospectively evaluated preoperative echocardiography of 1,319 consecutive liver transplant recipients (1,007 Non DM-ESLD vs. 312 DM-ESLD [23.7\%]) January 2012-May 2016. Systolic and diastolic indices, such as left ventricular ejection fraction, transmital E/A ratio, tissue doppler s', e' velocity, and E/e' ratio (index of left ventricular end-diastolic pressure), were compared using 1:2 propensity-score matching.

Results: DM-ESLD patients showed no differences in systolic indices of left ventricular ejection fraction and s' velocity, whereas diastolic indices of $E / A$ ratio $\leq 1$ (49.0\% vs. $40.2 \% \mathrm{P}=0.014)$, e' velocity (median $=7.0$ vs. $7.4 \mathrm{~cm} / \mathrm{s}, \mathrm{P}<0.001)$ and $\mathrm{E} / \mathrm{e}^{\prime}$ ratio $(10.9$ \pm 3.2 vs. $10.1 \pm 3.0, P<0.001$ ), showed worse diastolic function compare with Non DM-ESLD patients, respectively.

Conclusions: DM-ESLD patients suffer higher degree of diastolic dysfunction compared with Non DM-ESLD patients. Based on this, careful preoperative screening for diastolic dysfunction in DM-ESLD patients is encouraged, because poor transplant outcomes have been noted in patients with preoperative diastolic dysfunction.

Keywords: Diabetes mellitus; Diastolic heart failure; Echocardiography; Liver cirrhosis; Propensity score; Systolic heart failure.

\section{INTRODUCTION}

Diabetes mellitus (DM) is the most representative metabolic disorder with increasing prevalence. End-stage liver disease (ESLD) commonly causes metabolic disorders, especially disorders of glucose metabolism such as DM [1]. Fur- thermore, there has been a rapid increase in the incidence of ESLD resulting from non-alcoholic fatty liver disease, which is related to metabolic disorder. Therefore, the number of liver transplantation due to non-alcoholic fatty liver disease has increased in recent years [2,3]. As a result, there is increased interest in the effect of the interaction between disorders of

This is an Open Access article distributed under the terms of the Creative Commons Attribution Non-Commercial License (http://creativecommons.org/licenses/by-nc/4.0) which permits unrestricted non-commercial use, distribution, and reproduction in any medium, provided the original work is properly cited. 
glucose metabolism (such as DM) and ESLD [4,5].

The chronic cardiac dysfunction typically seen in ESLD is called cirrhotic cardiomyopathy. Increased baseline stroke volume (SV), decreased systemic vascular resistance, and increased heart rate are characteristics of this condition. The sympathetic nervous system becomes more active as baseline hepatic dysfunction worsens, thus increasing the baseline systolic function. However, collagen deposition within the myocardium causes left ventricular hypertrophy and increased myocardial stiffness, thereby decreasing the diastolic function [6]. Recently, the association between changes in cardiac function, especially diastolic dysfunction, and the prognosis of ESLD patients undergoing liver transplant has been actively investigated [6-8].

DM shows a high correlation with cardiac failure. DM-related cardiomyopathy (DM-CMP) is a known chronic cardiac disorder that characteristically occurs in patients with DM [9]. DM-CMP shows characteristics such as preceding diastolic dysfunction, systolic dysfunction, and left ventricular hypertrophy. DM-CMP is known to be caused by DM-related metabolic disorders, myocardial fibrosis, small vessel disease, cardiac autonomic neuropathy, and insulin resistance [10].

However, there is limited research on the difference in cardiac systolic or diastolic dysfunction between ESLD patients with DM (DM-ESLD) and ESLD patients without DM (Non DM-ESLD). Therefore, in this study, we aimed to evaluate the preoperative cardiac echocardiography data of liver transplant recipients to compare the systolic function and diastolic function in those with and without DM.

\section{MATERIALS AND METHODS}

This study retrospectively analyzed the echocardiography results of 1,572 adult ESLD patients who underwent liver transplant between January 2012 and June 2016. This study was conducted with approval from the Asan Medical Center Bioethics Committee (no. 2019-0107) and according to the ethical principles for medical research summarized in the 1975 Helsinki Declaration. Patients in whom DM was diagnosed by an endocrinologist before liver transplant and those with fasting glucose $\geq 126 \mathrm{mg} / \mathrm{dl}$, random glucose $\geq$ $200 \mathrm{mg} / \mathrm{dl}$, glucose level $\geq 200 \mathrm{mg} / \mathrm{dl}$ at $2 \mathrm{~h}$ after the oral administration of 75 g glucose, or hemoglobin $A_{1 c} \geq 6.5 \%$ were classified as having DM. Those without any diagnostic test results were classified into the control group. The severity of ESLD was evaluated using the Model for End-stage Liver Disease (MELD) score based on serum bilirubin, creatinine, and international normalized ratio. Patients aged $<18$ years, with a history of liver transplant, with concomitant chronic kidney disease, with a history of cardiac surgery or moderate to severe valvular disease, and without a preoperative echocardiogram were excluded. Demographic data, patient status before liver transplant, blood test results, and hemodynamic data were collected from electronic medical records. Transthoracic echocardiography was performed by a skilled technician using a Hewlett-Packard Sonos 2500 or 5500 im-
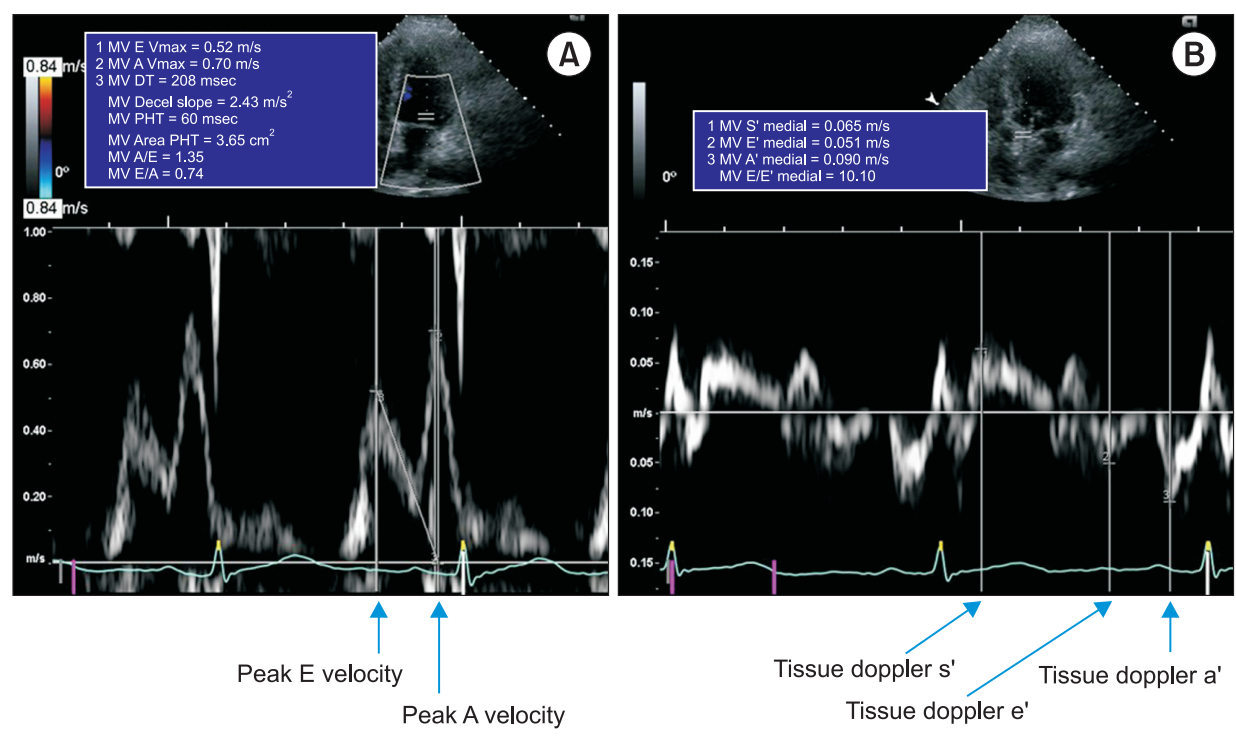

Fig. 1. Representative of echocardiographic measurement of $(A)$ transmitral peak $E$ velocity, peak $A$ velocity and (B) tissue doppler image of 's', e' and a' velocity. DT: deceleration time, $\mathrm{PHT}$ : pressure half-time. 
aging system (Hewlett-Packard Inc., USA) with a $2.5-\mathrm{MHz}$ transducer, and the measurements were confirmed by a cardiologist. The 2-dimensional variables measured included end-systolic interventricular diameter, end-diastolic interventricular diameter, end-systolic left ventricular posterior wall thickness, end-diastolic left ventricular posterior wall thickness, left ventricular mass index, and left atrial diameter. The Teichholz method or biplane modified Simpson's rule was used as appropriate to measure the left ventricular end-diastolic volume (EDV) and left ventricular end-systolic volume (ESV), which were used to calculate the SV (= EDV - ESV) and left ventricular ejection fraction (LVEF). The index of each measured value was calculated by dividing each value by the body surface area. In the apical 4-chamber view, pulsed-wave Doppler was used to measure early mitral inflow velocity (E), late mitral inflow velocity (A), deceleration time of the $\mathrm{E}$ wave, and $\mathrm{E} / \mathrm{A}$ ratio. The tissue Doppler image was used to measure the velocities of systolic wave ( $\left.\mathrm{s}^{\prime}\right)$, early diastolic wave ( $\left.\mathrm{e}^{\prime}\right)$, and late diastolic wave (a') on the luminal side of the septal mitral annulus. The E/e' ratio, which reflects the left ventricular end-diastolic pressure, was calculated (Fig. 1). For the evaluation of more complicated left ventricular end-systolic function, end-systolic elastance was calculated as ESV / end-systolic pressure. End systolic pressure, a reflec- tion of aortic pressure, was calculated as noninvasive systolic pressure $\times 0.9$. To evaluate vascular resistance, arterial elastance was calculated as end-systolic pressure / SV [11].

All values were expressed as mean \pm standard deviation, median (1st quartile, 3rd quartile), or number of patients (percent). Continuous variables were analyzed using the Shapiro-Wilk normality test and subsequent Student's $t$-test or Mann-Whitney test, as appropriate. Categorical variables were analyzed using the chi-square test or Fisher's exact test. To minimize the difference in baseline characteristics of the 2 groups, a 1:2 matched propensity score analysis [12] was performed. The propensity score, which is the probability of each subject to be assigned to the treatment group according to a given covariance, was calculated using a propensity score model via logistic regression analysis with the patient's age, sex, body mass index, MELD score, hypertension, history of cardiovascular disease, history of beta-blocker use, and btype natriuretic protein, among the characteristics specified in Table 1. Caliper matching was performed in a 1:2 ratio by using this propensity score in the nonrandom package (http://www.rdocumentation.org/packages/nonrandom) of $\mathrm{R}$, and the caliper was set as standard deviation*0.2. The model test for propensity scores was performed using Cstatistics and the Hosmer-Lemeshow test. R (version 3.3.1;

Table 1. Demographic of Enrolled Liver Transplant Recipients, Compared according to Prevalence of Diabetes

\begin{tabular}{|c|c|c|c|c|}
\hline Variable & $\begin{array}{l}\text { Without diabetes } \\
\qquad(n=1,007)\end{array}$ & $\begin{array}{l}\text { Diabetes } \\
(n=312)\end{array}$ & $P$ value & SMD \\
\hline Age (yr) & $53(48,58)$ & $55(51,61)$ & $<0.001$ & 0.383 \\
\hline Sex (male) & $742(74)$ & $246(79)$ & 0.078 & 0.122 \\
\hline Body mass index $\left(\mathrm{kg} / \mathrm{m}^{2}\right)$ & $23.6(21.6,25.6)$ & $23.4(21.1,25.6)$ & 0.340 & 0.062 \\
\hline Model for end-stage liver disease score & $13(9,20)$ & $12(9,18)$ & 0.213 & 0.180 \\
\hline Cardiovascular disease & $40(4)$ & $29(9)$ & $<0.001$ & 0.215 \\
\hline Hypertension & $129(13)$ & $83(27)$ & $<0.001$ & 0.352 \\
\hline Beta blocker use & $200(20)$ & $89(29)$ & 0.002 & 0.203 \\
\hline \multicolumn{5}{|l|}{ Etiology of liver cirrhosis } \\
\hline Hepatitis B virus & $615(61)$ & $178(57)$ & 0.230 & 0.082 \\
\hline Hepatitis C virus & $75(7)$ & $29(9)$ & 0.348 & 0.067 \\
\hline Alcoholic cirrhosis & $190(19)$ & $67(21)$ & 0.350 & 0.065 \\
\hline Biliary disease & $30(3)$ & $6(2)$ & 0.423 & 0.068 \\
\hline Other disease & $112(11)$ & $42(13)$ & 0.306 & 0.071 \\
\hline Combined hepatocellular carcinoma & 491 (49) & $163(52)$ & 0.312 & 0.070 \\
\hline \multicolumn{5}{|l|}{ Laboratory variables } \\
\hline Prothrombin time, INR & $1.36(1.17,1.76)$ & $1.36(1.18,1.58)$ & 0.258 & 0.193 \\
\hline Total bilirubin (mg/dl) & $1.9(1.0,5.9)$ & $1.8(1.0,3.8)$ & 0.116 & 0.258 \\
\hline Creatinine (mg/dl) & $0.75(0.63,0.92)$ & $0.76(0.64,1.00)$ & 0.286 & 0.006 \\
\hline B-type natriuretic peptide (pg/ml) & $45(20,99)$ & $49(25,104)$ & 0.352 & 0.019 \\
\hline
\end{tabular}

Values are presented as median (1Q, 3Q) or number (\%). SMD: standardized mean difference, INR: international normalized ratio. 
R Foundation for Statistical Computing, Austria) was used for statistical analysis, and paired $t$-test was used to analyze the difference between the 2 matched groups. $\mathrm{P}<0.05$ was deemed statistically significant.

\section{RESULTS}

Of 1,572 patients planned for liver transplant, 1,319 met the inclusion criteria. Of these patients, 312 (23.7\%) had diabetes. Table 1 summarizes the demographic data, cause of ESLD, blood test results, hemodynamic status, and echocardiogram results of the DM-ESLD and Non DM-ESLD groups.
DM-ESLD patients tended to be older and showed a greater incidence of accompanying cardiovascular disease such as hypertension, coronary artery disease, and cerebrovascular disease than Non DM-ESLD patients. DM-ESLD patients also tended to have a higher frequency of beta-blocker use. On echocardiograms, DM-ESLD patients showed decreased LVEF (64.6 $\pm 4.2 \%$ vs. $64.0 \pm 4.2 \%, \mathrm{P}=0.042)$ and systolic flow velocity ( $\left.\mathrm{s}^{\prime}\right)$ on tissue Doppler (8.4 [7.5-9.5] cm/s vs. 8.2 [7.2-9.1] cm/s, P = 0.003) compared with Non DM-ESLD patients, suggesting decreased left ventricular systolic function. Further, the E/A ratio, a marker for diastolic dysfunction, was lower (1.16 [0.90-1.40] vs. $1.02[0.84-1.27], \mathrm{P}<0.001)$;

Table 2. Echocardiography of Enrolled Liver Transplant Recipients, Compared according to Prevalence of Diabetes

\begin{tabular}{|c|c|c|c|}
\hline Variable & $\begin{array}{l}\text { Without diabetes } \\
\qquad(n=1,007)\end{array}$ & $\begin{array}{l}\text { Diabetes } \\
(n=312)\end{array}$ & $P$ value \\
\hline \multicolumn{4}{|l|}{ Hemodynamic values } \\
\hline Systolic blood pressure (mmHg) & $106(97,118)$ & $106(98,116)$ & 0.943 \\
\hline Diastolic blood pressure (mmHg) & $67(61,75)$ & $68(61,74)$ & 0.987 \\
\hline End systolic pressure (mmHg) & $95(87,106)$ & $96(88,104)$ & 0.943 \\
\hline Arterial elastance & $1.38(1.12,1.70)$ & $1.37(1.12,1.71)$ & 0.948 \\
\hline End-systolic elastance & $2.52(2.03,3.16)$ & $2.45(2.03,3.09)$ & 0.467 \\
\hline \multicolumn{4}{|l|}{ Left ventricular structures and Systolic Functional values } \\
\hline LV dimension in systole (mm) & $30(27,33)$ & $30(27,33)$ & 0.830 \\
\hline LV dimension in diastole (mm) & $50(47,54)$ & $50(47,53)$ & 0.385 \\
\hline LV posterior wall thickness in systole (mm) & $14(13,15)$ & $14(13,15)$ & 0.684 \\
\hline LV posterior wall thickness in diastole (mm) & $9(8,10)$ & $9(8,10)$ & 0.417 \\
\hline Interventricular septal thickness in systole (mm) & $13(12,14)$ & $14(12,15)$ & 0.137 \\
\hline Interventricular septal thickness in diastole (mm) & $9(8,10)$ & $9(8,10)$ & 0.472 \\
\hline Left atrium (mm) & $39(36,43)$ & $39(36,43)$ & 0.190 \\
\hline Aorta $(\mathrm{mm})$ & $33(30,35)$ & $33(31,36)$ & 0.001 \\
\hline End-systolic volume (ml) & $39(31,46)$ & $40(31,48)$ & 0.393 \\
\hline End-diastolic volume (ml) & $109(90,132)$ & $109(90,132)$ & 0.843 \\
\hline Stroke volume $(\mathrm{ml})$ & $69(58,85)$ & $71(57,84)$ & 0.908 \\
\hline Stroke volume index & $41(34,48)$ & $41(34,48)$ & 0.830 \\
\hline $\operatorname{LVMI}\left(\mathrm{g} / \mathrm{m}^{2}\right)$ & $88(76,102)$ & $90(76,102)$ & 0.842 \\
\hline LV ejection fraction (\%) & $64.6 \pm 4.2$ & $64.0 \pm 4.2$ & 0.042 \\
\hline $\mathrm{s}^{\prime}$ medial (cm/s) & $8.4(7.5,9.5)$ & $8.2(7.2,9.1)$ & 0.003 \\
\hline \multicolumn{4}{|l|}{ Diastolic function and RV function } \\
\hline E/A ratio & $1.16(0.90,1.40)$ & $1.02(0.84,1.27)$ & \\
\hline $\mathrm{E} / \mathrm{A}$ ratio $\leq 1.0$ & $354(35.2)$ & $154(49.4)$ & $<0.001$ \\
\hline E/A ratio $>1.0$ & $653(64.8)$ & $158(50.6)$ & $<0.001$ \\
\hline Peak E velocity (cm/s) & $74(61,88)$ & $72(62,85)$ & 0.268 \\
\hline Peak A velocity $(\mathrm{cm} / \mathrm{s})$ & $64(54,76)$ & $69(58,82)$ & $<0.001$ \\
\hline Deceleration time (ms) & $210(183,238)$ & $214(185,240)$ & 0.358 \\
\hline $\mathrm{e}^{\prime}$ medial (cm/s) & $7.7(6.5,8.9)$ & $7.0(5.9,8.1)$ & $<0.001$ \\
\hline$a^{\prime}$ medial $(\mathrm{cm} / \mathrm{s})$ & $9.4(8.1,10.7)$ & $9.4(8.1,10.5)$ & 0.810 \\
\hline$E / e^{\prime}$ & $9.0(8.0,12.0)$ & $10.0(9.0,13.0)$ & $<0.001$ \\
\hline Peak TR velocity $(\mathrm{m} / \mathrm{s})$ & $2.4(2.2,2.5)$ & $2.3(2.2,2.5)$ & 0.411 \\
\hline RV PGsys (mmHg) & $23(19,25)$ & $21(19,25)$ & 0.411 \\
\hline
\end{tabular}

Values are presented as median (1Q, 3Q), mean \pm SD, or number (\%). LV: left ventricle, LVMI: left ventricular mass index, E/A: early and late diastolic velocity ratio, E/e': ratio of early diastolic to tissue doppler imaging velocities, TR: tricuspid regurgitation, RV: right ventricle, PGsys: systolic pressure gradient. 
the e' velocity was lower $(7.7$ [6.5-8.9] cm/s vs. 7.0 [5.9-8.1], $\mathrm{P}<0.001$ ); and $\mathrm{E} / \mathrm{e}^{\prime}$, a marker of left ventricular end-diastolic pressure, was higher (9.0 [8.0-12.0] vs. 10.0 [9.0-13.0], $\mathrm{P}<$ 0.001 ) in DM-ESLD patients (Table 2).

Table 3 shows the results of 1:2 propensity matching, which involved 306 DM-ESLD patients and 607 Non DM-ESLD patients (1:1.98). The C-statistics value of the propensity score model was 0.662 , and the calibration by Hosmer-Lemeshow statistics showed $\chi^{2}=12.113, \mathrm{df}=8$, and $\mathrm{P}=0.1462$. Baseline variables that showed a difference between the 2 groups before matching showed $\mathrm{P}>0.05$ after matching (Table 3 ). On echocardiograms, systolic function indices that were significant before matching (LVEF, s' velocity; both $\mathrm{P}>0.05$ ) did not show a significant difference after matching (Fig. 2). However, diastolic function indices including E/A ratio (1.09

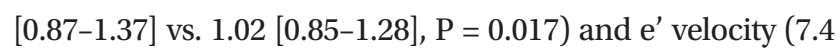

Table 3. Demographic Liver Transplant Recipients after 1:2 Propensity Score Matching, Compared according to Prevalence of Diabetes

\begin{tabular}{|c|c|c|c|c|}
\hline Variable & $\begin{array}{l}\text { Without diabetes } \\
\qquad(n=607)\end{array}$ & $\begin{array}{l}\text { Diabetes } \\
(n=306)\end{array}$ & P value & SMD \\
\hline Age (yr) & $55 \pm 6.9$ & $55 \pm 7.5$ & 0.880 & 0.010 \\
\hline Sex (male) & $491(81)$ & $241(79)$ & 0.500 & 0.053 \\
\hline Body mass index $\left(\mathrm{kg} / \mathrm{m}^{2}\right)$ & $23.5(21.4,25.5)$ & $23.4(21.0,25.6)$ & 0.675 & 0.020 \\
\hline Model for end-stage liver disease score & $12(8,18)$ & $12(9,18)$ & 0.348 & 0.011 \\
\hline Cardiovascular disease & $37(6)$ & $26(8)$ & 0.225 & 0.092 \\
\hline Hypertension & $125(21)$ & $77(25)$ & 0.137 & 0.109 \\
\hline Beta blocker use & $159(26)$ & $86(28)$ & 0.592 & 0.043 \\
\hline \multicolumn{5}{|l|}{ Etiology of liver cirrhosis } \\
\hline Hepatitis B virus & $377(62)$ & $177(58)$ & 0.240 & 0.087 \\
\hline Hepatitis $C$ virus & $56(9)$ & $29(9)$ & 0.998 & 0.009 \\
\hline Alcoholic cirrhosis & $116(19)$ & $65(21)$ & 0.500 & 0.053 \\
\hline Biliary disease & $11(2)$ & $6(2)$ & 1.000 & 0.011 \\
\hline Other disease & $58(10)$ & $39(13)$ & 0.173 & 0.101 \\
\hline Combined hepatocellular carcinoma & $323(53)$ & $162(53)$ & 0.994 & 0.005 \\
\hline \multicolumn{5}{|l|}{ Laboratory variables } \\
\hline Prothrombin time, INR & $1.32(1.14,1.60)$ & $1.36(1.18,1.58)$ & 0.315 & 0.025 \\
\hline Total bilirubin (mg/dl) & $1.6(0.9,4.2)$ & $1.8(1.0,3.9)$ & 0.553 & 0.112 \\
\hline Creatinine (mg/dl) & $0.77(0.66,0.92)$ & $0.76(0.63,1.00)$ & 0.854 & 0.014 \\
\hline B-type natriuretic peptide (pg/ml) & $47(22,103)$ & $49(23,104)$ & 0.956 & 0.053 \\
\hline
\end{tabular}

Values are presented as mean $\pm \mathrm{SD}$, number (\%), or median (1Q, 3Q). Propensity score model discrimination was evaluated with c-statistics $(\mathrm{c}=0.662)$ and calibration was assessed with Hosmer-Lemeshow statistics (X-squared $=12.113$, $\mathrm{df}=8, \mathrm{P}$ value $=0.1462$ ). SMD: standardized mean difference, INR: international normalized ratio.
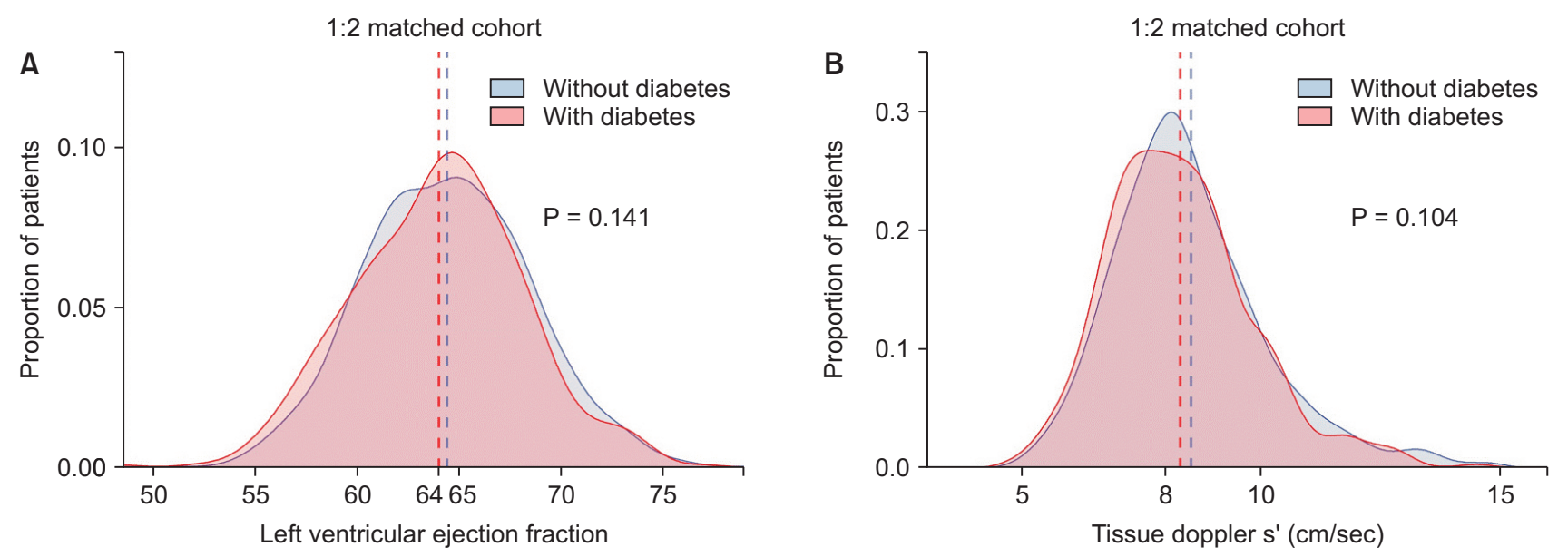

Fig. 2. Comparison of systolic function in matched set. Density histograms depict frequency of (A) left ventricular ejection fraction and (B) tissue doppler s' velocity. Vertical dashed lines show mean value for left ventricular ejection fraction and median for tissue doppler s' velocity (both $\mathrm{P}>0.1$ ). 
[6.4-8.5] $\mathrm{cm} / \mathrm{s}$ vs. $7.0[5.9-8.1] \mathrm{cm} / \mathrm{s}, \mathrm{P}<0.001)$ were still low in DM-ESLD patients, whereas the $\mathrm{E} / \mathrm{e}^{\prime}$ ratio, a marker of left ventricular end-diastolic pressure, was still high (10.1 \pm 3.0 vs.10.9 \pm 3.2 , P < 0.001) (Table 4, Fig. 3).

\section{DISCUSSION}

The main finding of this study is that DM-ESLD patients showed worse left ventricular diastolic function compared to Non DM-ESLD patients, whereas no difference in left ventricular systolic function was found. While it is normal for
ESLD patients to show diastolic relaxation dysfunction, DMESLD patients showing more severe diastolic dysfunction implies that DM exacerbates cardiac diastolic dysfunction in ESLD patients. On the other hand, left ventricular systolic function was slightly worse in Non DM-ESLD patients before matching, but there was no significant difference between the 2 groups after matching for age, sex, beta-blocker use, and other factors.

Recently, the transplant rejection and mortality rates after liver transplant have decreased drastically owing to improvements in surgical skills as well as successful intraoperative

Table 4. Echocardiography of Liver Transplant Recipients after 1:2 Propensity Score Matching, Compared according to Prevalence of Diabetes

\begin{tabular}{|c|c|c|c|}
\hline Variable & $\begin{array}{l}\text { Without diabetes } \\
\qquad(\mathrm{n}=607)\end{array}$ & $\begin{array}{l}\text { Diabetes } \\
(n=306)\end{array}$ & P value \\
\hline \multicolumn{4}{|l|}{ Hemodynamic values } \\
\hline Systolic blood pressure (mmHg) & $106(97,117)$ & $107(98,117)$ & 0.390 \\
\hline Diastolic blood pressure (mmHg) & $67(60,75)$ & $68(61,74)$ & 0.879 \\
\hline End systolic pressure (mmHg) & $95(87,105)$ & $96(88,105)$ & 0.390 \\
\hline Arterial elastance & $1.39(1.14,1.70)$ & $1.37(1.12,1.71)$ & 0.799 \\
\hline End-systolic elastance & $2.53(2.04,3.14)$ & $2.45(2.02,3.09)$ & 0.477 \\
\hline \multicolumn{4}{|l|}{ Left ventricular structures and Systolic Functional values } \\
\hline LV dimension in systole (mm) & $30 \pm 4$ & $30 \pm 5$ & 0.303 \\
\hline LV dimension in diastole $(\mathrm{mm})$ & $50(47,53)$ & $50(47,53)$ & 0.748 \\
\hline LV posterior wall thickness in systole (mm) & $14(13,15)$ & $14(13,15)$ & 0.911 \\
\hline LV posterior wall thickness in diastole $(\mathrm{mm})$ & $9(8,10)$ & $9(8,10)$ & 0.826 \\
\hline Interventricular septal thickness in systole (mm) & $13(12,14)$ & $14(12,15)$ & 0.380 \\
\hline Interventricular septal thickness in diastole (mm) & $9(8,10)$ & $9(8,10)$ & 0.905 \\
\hline Left atrium (mm) & $39(36,43)$ & $39(36,43)$ & 0.742 \\
\hline Aorta $(\mathrm{mm})$ & $33(30,35)$ & $33(31,36)$ & 0.099 \\
\hline End-systolic volume (ml) & $39(31,46)$ & $40(31,48)$ & 0.251 \\
\hline End-diastolic volume (ml) & $108(91,128)$ & $109(90,132)$ & 0.387 \\
\hline Stroke volume $(\mathrm{ml})$ & $68(58,84)$ & $71(57,84)$ & 0.496 \\
\hline Stroke volume index & $40(34,47)$ & $41(34,48)$ & 0.581 \\
\hline $\operatorname{LVMI}\left(\mathrm{g} / \mathrm{m}^{2}\right)$ & $89(76,103)$ & $90(76,102)$ & 0.995 \\
\hline LV ejection fraction (\%) & $64.4 \pm 4.1$ & $64.0 \pm 4.2$ & 0.141 \\
\hline $\mathrm{s}^{\prime}$ medial $(\mathrm{cm} / \mathrm{s})$ & $8.3(7.5,9.4)$ & $8.2(7.2,9.1)$ & 0.104 \\
\hline \multicolumn{4}{|l|}{ Diastolic function and RV function } \\
\hline E/A ratio & $1.09(0.87,1.37)$ & $1.02(0.85,1.28)$ & \\
\hline E/A ratio $\leq 1$ & $244(40.2)$ & $150(49.0)$ & 0.017 \\
\hline E/A ratio $>1$ & $363(59.8)$ & $156(51.0)$ & 0.014 \\
\hline Peak E velocity (cm/s) & $71(60,86)$ & $72(62,85)$ & 0.475 \\
\hline Peak A velocity $(\mathrm{cm} / \mathrm{s})$ & $64(54,76)$ & $68(58,81)$ & $<0.001$ \\
\hline Deceleration time (ms) & $214(186,244)$ & $214(185,239)$ & 0.679 \\
\hline$e^{\prime}$ medial (cm/s) & $7.4(6.4,8.5)$ & $7.0(5.9,8.1)$ & $<0.001$ \\
\hline$a^{\prime}$ medial $(\mathrm{cm} / \mathrm{s})$ & $9.4(8.2,10.6)$ & $9.4(8.1,10.5)$ & 0.427 \\
\hline$E / e^{\prime}$ & $10.1 \pm 3.0$ & $10.9 \pm 3.2$ & $<0.001$ \\
\hline Peak TR velocity (m/s) & $2.4(2.2,2.5)$ & $2.3(2.2,2.5)$ & 0.516 \\
\hline RV PGsys (mmHg) & $23(19,25)$ & $21(19,25)$ & 0.516 \\
\hline
\end{tabular}

Values are presented as median (1Q, 3Q), mean \pm SD, or number (\%). LV: left ventricle, LVMI: left ventricular mass index, E/A: early and late diastolic velocity ratio, E/e': ratio of early diastolic to tissue doppler imaging velocities, TR: tricuspid regurgitation, RV: right ventricle, PGsys: systolic pressure gradient. 
1:2 matched cohort

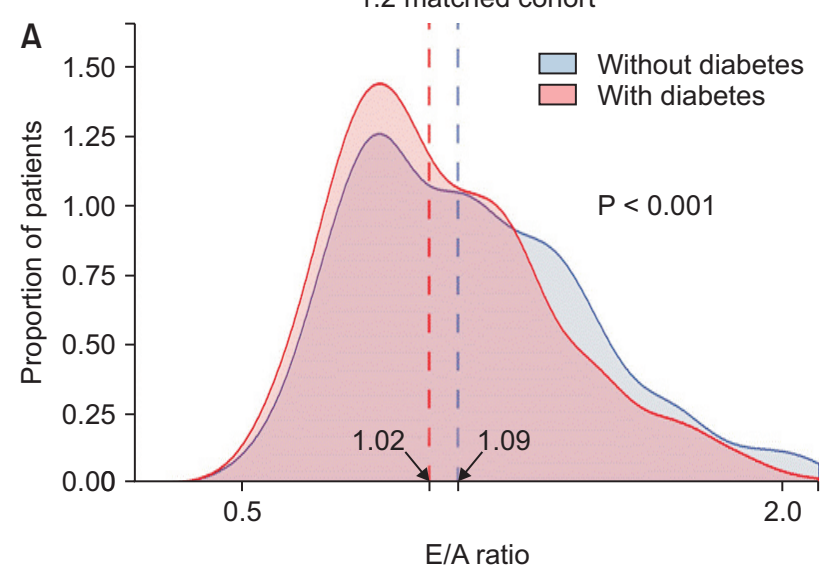

1:2 matched cohort

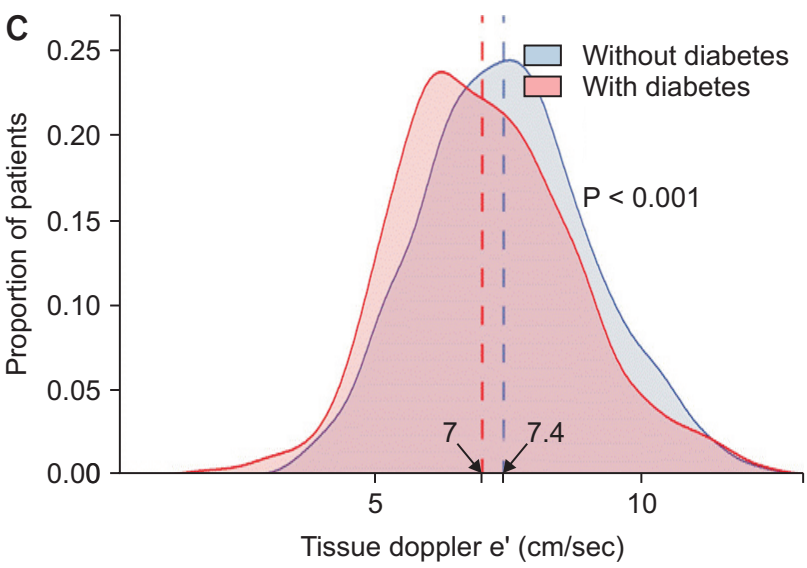

anesthetic management. Early complications and death after liver transplant depend largely on the severity of preoperative cirrhotic cardiomyopathy as well as the presence of cardiovascular disease, such as coronary artery disease [13]. Therefore, preoperative cardiac assessment before liver transplant is crucial and currently, all patients now undergo preoperative echocardiography. In particular, many of the recent studies focused on the cardiac diastolic dysfunction $[6,14]$. According to Mittal et al. [8], patients with accompanying left ventricular diastolic dysfunction before liver transplant show higher rates of transplant rejection and death [15]. Therefore, considering these results as well as the results of the current study, the decrease in cardiac function in DM-ESLD patients may exert adverse effects on postoperative cardiac failure and the viability of the transplanted liver. Hence, this topic requires further research.

After DM-CMP was introduced by Lundbeck in 1954 [16], this condition has been the subject of many studies. Twenty years after the term was coined, Rubler et al. [17] showed

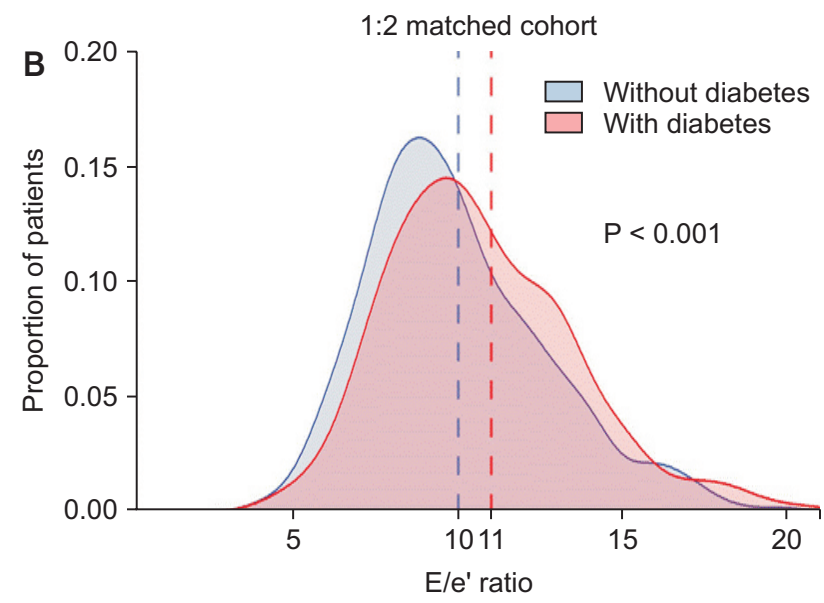

Fig. 3. Comparison of diastolic function in matched set. Density histograms depict frequency of (A) transmitral E/A ratio, (B) E/e' ratio and (C) tissue doppler e' velocity. Vertical dashed lines show median value for $E / A$ ratio and e' velocity while mean values for $E / e^{\prime}$ ratio (all $P<0.001$ ).

evidence that DM-CMP is directly caused by DM rather than by complications of DM such as coronary artery disease. In other words, the mechanism behind DM-CMP is believed to be microvascular disease and myocardial metabolic dysfunction due to DM. DM-CMP was classified as a dilated phenotype with eccentric left ventricular remodeling and systolic dysfunction, similar to the pathophysiology of dilated cardiomyopathy [9]. However, with the increased incidence of type 2 DM, elderly, obese, female patients, who comprise the majority of patients with DM, have shown characteristics such as a small left ventricle, thick ventricular walls, a large left atrium, and normal LVEF. In other words, unlike the previously known phenotype, DM-CMP now mainly shows features of a restrictive phenotype with concentric left ventricular remodeling and diastolic dysfunction [18], similar to those of heart failure with preserved ejection fraction (HFpEF), which account for the majority of heart failure cases [19].

In summary, the recently emerging restrictive phenotype of DM-CMP tends to manifest similarly to HFpEF [9]. We pre- 
dicted that there is a possibility of alleviation of diastolic dysfunction in patients with DM considering that ESLD patients experience cirrhotic cardiomyopathy with increased left ventricular size. However, we found that DM-ESLD patients show exacerbation of diastolic dysfunction. This is probably because DM worsens the cardiac diastolic dysfunction in ESLD patients. In addition, before matching, DM-ESLD patients showed a higher rate of concomitant cardiovascular disease, such as coronary artery disease, than Non DM-ESLD patients. However, in this study, we only analyzed the presence of cardiovascular disease after negating a significant difference with propensity score matching, in order to consider the effect of DM alone.

This study has a few limitations. First, owing to the retrospective nature of this study, the causality between DM and ESLD is unclear. It is not known whether DM developed before ESLD or secondarily according to the progress of ESLD; thus, more detailed research is needed. Second, this is a single-center study and multicenter prospective studies are needed in the future. Third, although E/A ratio $<1$ on Doppler echocardiography means mild diastolic dysfunction, E/ A > 1 can either mean normal diastolic function or moderate pseudo-normalization. Although E/A ratio $<1$ is specified in the 2005 definition of cirrhotic cardiomyopathy, the E/A ratio alone is not enough as a criterion for diastolic dysfunction and other markers of diastolic dysfunction are needed. Fourth, cardiac diastology is not yet well established and new guidelines on grading have been published by American and European cardiology societies [20,21]. In the future, studies that compare surgical outcomes using these guidelines would be necessary. Fifth, this study showed that DM-ESLD patients have a higher incidence of diastolic dysfunction, but the mechanism and pathophysiology behind this observation have not been studied. More research is needed on this topic.

In conclusion, in the comparison of the systolic and diastolic function of DM-ESLD and Non DM-ESLD patients based on preoperative echocardiograms, DM-ESLD patients showed similar systolic function but worse diastolic function. Therefore, preservation of postoperative cardiac function and the transplanted liver is essential in DM-ESLD patients, considering that ESLD patients with accompanying left ventricular diastolic dysfunction showed higher mortality and transplant rejection rates. Further prospective studies are needed on this topic.

\section{SUPPLEMENTARY MATERIALS}

Supplementary data containing Korean version of this article is available at https://doi.org/10.17085/apm.2019.14.4.465.

\section{CONFLICTS OF INTEREST}

No potential conflict of interest relevant to this article was reported.

\section{ORCID}

Hye-Mee Kwon: https://orcid.org/0000-0001-7788-9555

Youngil Jeong: https://orcid.org/0000-0003-2157-2369

Kyoung-Sun Kim: https://orcid.org/0000-0002-6643-9177

Kyeo-Woon Jung: https://orcid.org/0000-0001-6305-6296

Young-Jin Moon: https://orcid.org/0000-0003-3719-1691

\section{REFERENCES}

1. Elkrief L, Rautou PE, Sarin S, Valla D, Paradis V, Moreau R. Diabetes mellitus in patients with cirrhosis: clinical implications and management. Liver Int 2016; 36: 936-48.

2. Wong RJ, Cheung R, Ahmed A. Nonalcoholic steatohepatitis is the most rapidly growing indication for liver transplantation in patients with hepatocellular carcinoma in the U.S. Hepatology 2014; 59: 2188-95.

3. Charlton MR, Burns JM, Pedersen RA, Watt KD, Heimbach JK, Dierkhising RA. Frequency and outcomes of liver transplantation for nonalcoholic steatohepatitis in the United States. Gastroenterology 2011; 141: 1249-53.

4. Lim S, Oh TJ, Koh KK. Mechanistic link between nonalcoholic fatty liver disease and cardiometabolic disorders. Int J Cardiol 2015; 201: 408-14.

5. Lim S, Taskinen MR, Borén J. Crosstalk between nonalcoholic fatty liver disease and cardiometabolic syndrome. Obes Rev 2019; 20: 599-611.

6. Kwon HM, Hwang GS. Cardiovascular dysfunction and liver transplantation. Korean J Anesthesiol 2018; 71: 85-91.

7. Ruíz-del-Árbol L, Achécar L, Serradilla R, Rodríguez-Gandía MÁ, Rivero M, Garrido E, et al. Diastolic dysfunction is a predictor of poor outcomes in patients with cirrhosis, portal hypertension, and a normal creatinine. Hepatology 2013; 58: 1732-41.

8. Mittal C, Qureshi W, Singla S, Ahmad U, Huang MA. Pre-transplant left ventricular diastolic dysfunction is associated with post transplant acute graft rejection and graft failure. Dig Dis Sci 2014; 
59: 674-80.

9. Seferović PM, Paulus WJ. Clinical diabetic cardiomyopathy: a two-faced disease with restrictive and dilated phenotypes. Eur Heart J 2015; 36: 1718-27, 1727a-1727c.

10. Hamby RI, Zoneraich S, Sherman L. Diabetic cardiomyopathy. JAMA 1974; 229: 1749-54.

11. Shin WJ, Song JG, Jun IG, Moon YJ, Kwon HM, Jung K, et al. Effect of ventriculo-arterial coupling on transplant outcomes in cirrhotics: analysis of pressure-volume curve relations. J Hepatol 2017; 66: 328-37.

12. Lee DK. An introduction to propensity score matching methods. Anesth Pain Med 2016; 11: 130-48.

13. VanWagner LB, Lapin B, Levitsky J, Wilkins JT, Abecassis MM, Skaro AI, et al. High early cardiovascular mortality after liver transplantation. Liver Transpl 2014; 20: 1306-16.

14. Steadman RH, Wray CL. Cardiovascular assessment of the liver transplantation candidate. Int Anesthesiol Clin 2017; 55: 42-66.

15. Sang BH, Kim JW, Yoo JI, Bang YS, Choi YS, Moon YJ, et al. Pretransplant diastolic wall strain assessed by transthoracic echocardiography and its implication on posttransplant survival rate in liver transplantation. Anesth Pain Med 2017; 12: 159-64.

16. Lundbaek K. Diabetic angiopathy: a specific vascular disease. Lancet 1954; 266: 377-9.
17. Rubler S, Dlugash J, Yuceoglu YZ, Kumral T, Branwood AW, Grishman A. New type of cardiomyopathy associated with diabetic glomerulosclerosis. Am J Cardiol 1972; 30: 595-602.

18. Forbes JM, Cooper ME. Mechanisms of diabetic complications. Physiol Rev 2013; 93: 137-88.

19. Paulus WJ, Tschöpe C, Sanderson JE, Rusconi C, Flachskampf FA, Rademakers FE, et al. How to diagnose diastolic heart failure: a consensus statement on the diagnosis of heart failure with normal left ventricular ejection fraction by the Heart Failure and Echocardiography Associations of the European Society of Cardiology. Eur Heart J 2007; 28: 2539-50.

20. Nagueh SF, Smiseth OA, Appleton CP, Byrd BF 3rd, Dokainish H, Edvardsen T, et al. Recommendations for the evaluation of left ventricular diastolic function by echocardiography: an update from the American Society of Echocardiography and the European Association of Cardiovascular Imaging. Eur Heart J Cardiovasc Imaging 2016; 17: 1321-60.

21. Nagueh SF, Smiseth OA, Appleton CP, Byrd BF 3rd, Dokainish H, Edvardsen T, et al. Recommendations for the evaluation of left ventricular diastolic function by echocardiography: an update from the American Society of Echocardiography and the European Association of Cardiovascular Imaging. J Am Soc Echocardiogr 2016; 29: 277-314. 